Ärztliche Erfahrung beschränkt sich nicht auf medizinisches Fachwissen.

Sie entsteht auch aus den mehr oder minder alltäglichen, heiter, ärgerlich oder nachdenklich stimmenden Erlebnissen mit Patienten, Kollegen und Mitarbeitern. Senden Sie uns Ihre Geschichte an: cornelius.heyer@springer.com.

\title{
Ärztekinder erweitern ihren Wortschatz
}

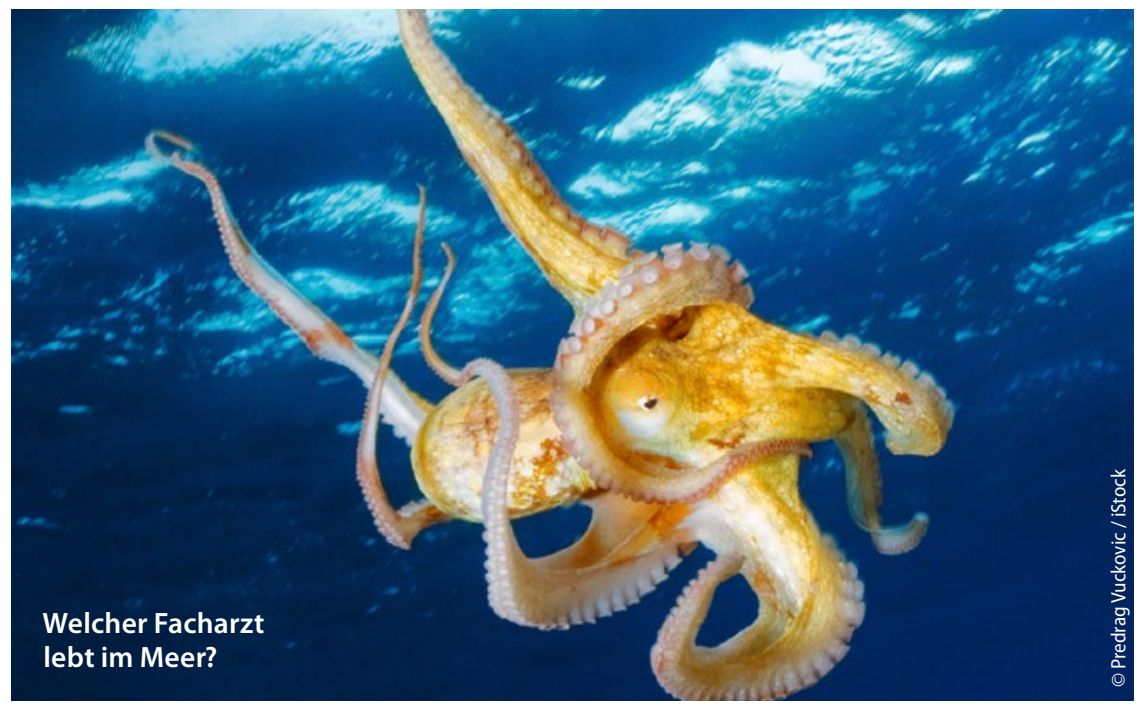

Ganz zwangsläufig werden meine Kinder in die Welt der Medizin eingeführt. Es kommt häufig vor, dass ich zu Hause von der Arbeit oder von Fortbildungen erzähle, oder dass wir die Familien von Kollegen treffen. Wie sehr sich aber dadurch der Wortschatz meiner Kinder von dem ihrer Altersgenossen unterscheidet, wurde uns deutlich, als mein Sohn neulich aus der Grundschule kam und uns begeistert von einer Naturdokumentation erzählte, die dort gezeigt worden war: „Stell dir vor, Mutti, in der Tiefsee, da gibt es bunte Orthopäden!“ Dieses Wort war ihm offenbar geläufiger als „Oktopoden“.

Dr. Andrea Linsel, Lüneburg

\section{Erfreuliche Befunde lösen Wutanfall aus}

_ Betritt ein Patient mit einer Begleitperson das Sprechzimmer, frage ich oft scherzhaft: „Wer von Ihnen ist denn nun der Patient?" Manchmal ist diese Frage gar nicht so einfach zu klären.

Neulich saß ein Ehepaar im mittleren Alter in meinem Sprechzimmer. Die Ehefrau war laut Patientenakte die eigentliche Patientin, meist sprach aber der Ehemann. Er beklagte wortreich eine Unzahl von „rheumatischen Beschwerden“, die sie plagten. Es müsse etwas ganz Schlimmes sein, an dem sie da litt.

Um dem auf den Grund zu gehen, führte ich zunächst eine gründliche kör- perliche Untersuchung durch. Dann ließ ich mich auf eine ganze Batterie von allgemeinen Labor- und speziellen Rheumatests ein, um nur ja keine Differenzialdiagnose zu übersehen.

Am Ende kam - wie so oft - nichts dabei heraus. Ich verfasste den Arztbrief und schickte ihn der Patientin. Wenige Tage später bekam ich einen wütenden Anruf von dem Ehemann. Er sei mit meiner Befunderhebung überhaupt nicht einverstanden, beschimpfte er mich. Er drohte sogar mit rechtlichen Schritten, sollte ich nicht umgehend alle Unterlagen vernichten und alle Eintra- gungen in der elektronischen Patientenakte löschen. Ich versuchte, ihn zu beruhigen, indem ich alle Befunde noch einmal ausführlich erläuterte - aber er wollte es nicht hören.

Ich erkannte zu spät, wie stark sich beide in ihrer Krankheitswelt eingerichtet hatten, und dass sie eigentlich gar keine Lösung, sondern nur eine Bestätigung für ein schlimmes Leiden suchten, um so weitermachen zu können wie bisher. Noch nicht einmal von der Diagnose „Fibromyalgie“ wollte der Mann etwas hören.

Dr. Reinhard Klofat, Meerbusch 